\title{
Surgical Treatment of Dorsolumbar Spine Tuberculosis by Posterior Decompression, Stabilization with Transpedicular Screws and Rods and Fusion
}

\author{
Apel Chandra Saha ${ }^{1}$, Snriti Kona Kabiraj ${ }^{2}$, Md. Rezwanur Rahman ${ }^{3}$, Shahana Shermin ${ }^{4}$, \\ Md. Hasan Masud ${ }^{5}$, Muhammad Awlad Hossain ${ }^{6}$
}

\begin{abstract}
Background: Spinal tuberculosis is a medical disease and antitubercular drugs play the main role in the recovery of patients. However, with proper indication, surgical procedures are superior in the prevention of neurological deterioration, maintenance of stability, early recovery and early mobilization. Modern method of surgical intervention of dorsolumbar tuberculosis is posterior decompression, stabilization with transpedicular screws and rods and fusion. Objective: To evaluate the efficacy of posterior decompression, stabilization by transpedicular screws and rods and fusion in patients with spinal TB in thoracic and lumbar region. Materials and method: This is a prospective interventional study carried out at National Institute of Traumatology \& Orthopaedic Rehabilitation (NITOR), Dhaka, Bangladesh and different private hospitals in Dhaka from October, 2012 to December, 2014. Total number of patients was 12; among them 7 were male and 5 were female, age ranged from 21-60 years with a follow up period of 12 months to 18 months. Results: More common site of tubercular lesion was at dorsal spines (58.73\%). In this study the patients were preoperatively classified according to American Spinal Injury Association (ASIA) Impairment Scale and among the patients 1 was ASIA-A, 2 were ASIA-B, 5 were ASIA-C, 3 were ASIA-D, and 1 was ASIA-E. In postoperative state 1 patient was ASIA-B, 3 patients were ASIA-D and 8 were ASIA-E. Maximum patients (75\%) had bony fusion grade 1. More than $80 \%$ subjects had good outcome. Conclusion: Posterior decompression, stabilization with transpedicular screws and rods and fusion is a satisfactory surgical modality of treatment of dorsolumbar spinal tuberculosis.
\end{abstract}

Keywords: Dorsolumbar TB; posterior decompression; transpedicular; screws and rods.

$$
\text { Delta Med Col J. Jul 2016;4(2):71- } 76
$$

\section{Introduction}

Vertebral tuberculosis (TB) is the commonest form of skeletal tuberculosis and it constitutes about $50 \%$ of all cases of tuberculosis of bone and joints. ${ }^{1}$ Bone and joint tuberculosis accounts

1. Jr. Consultant, Upazilla Health Complex, Debidwar, Comilla, Bangladesh.

2. Jr. Consultant, Upazilla Health Complex, Ashuganj, Brahmanbaria, Bangladesh.

3. Professor, Department of Biochemistry, Delta Medical College, Dhaka, Bangladesh.

4. Senior Medical Officer, Department of Gynae \& Obs., BIRDEM General Hospital, Dhaka, Bangladesh.

5. Associate Professor, National Institute of Traumatology \& Orthopaedic Rehabilitation (NITOR), Dhaka, Bangladesh.

6. Jr. Consultant, OSD, DGHS, Dhaka, Bangladesh.

Correspondence: Dr. Apel Chandra Saha. e-mail: cityhosp.bd@gmail.com 
approximately $15 \%$ to $38 \%$ of extra pulmonary form of the disease and $1 \%$ to $5 \%$ of all the cases of TB. Spinal TB can affect any segment of the lower thoracic and the lumbar vertebrae. ${ }^{2}$

Spinal tuberculosis was initially described by Sir Percival Pott (1779) as a painful kyphotic deformity of the spine associated with paraplegia. ${ }^{3}$ The disease spreads to the spine from primary focus either directly or through blood i.e. intercostal arteries and Batson's venous plexus. ${ }^{4}$ Blood borne infection usually settles in a vertebral body adjacent to the intervertebral disc. Bone destruction and caseation follow, with infection spreading to the disc space and to the adjacent vertebrae. ${ }^{4}$ As the vertebrae collapse into each other, a sharp angulation is formed which produces kyphosis. Caseation and cold abscess formation may extend to neighboring vertebrae or escape into the paravertebral soft tissue. There is a major risk of cord damage due to pressure by the abscess or displaced bone or ischaemia from spinal artery thrombosis. ${ }^{4}$

Any part of spinal column may be affected by tuberculosis but it is most commonly found in the lower thoracic and thoracolumbar region. The order of frequency has been dorsal (42\%), lumbar $(26 \%)$, dorsolumbar $(12 \%)$, cervical $(12 \%)$ and sacral $(3 \%){ }^{1}$

Spinal TB is a medical disease and antitubercular drugs play the main role in the recovery of patients. ${ }^{5}$ If there is no complication and if the lesion is limited to the vertebrae, antitubercular chemotherapy can treat TB. ${ }^{2}$ However, with proper indication, surgical procedures are superior in the prevention of neurological deterioration, maintenance of stability, early recovery and early mobilization. ${ }^{2}$ The most popular protocol for anti TB chemotherapy is to use rifampicin, isoniazid, ethambutol and pyrazinamide for initial two months followed by a maintenance phase of rifampicin and isoniazid for six, nine, twelve or eighteen months. ${ }^{6}$
The principle of surgical intervention of spinal TB is to decompress the spinal cord by removing the necrotic tissue and draining of any pus and devitalized tissue followed by immobilization. Yet the infected vertebrae are prone to collapse and they require mechanical support to prevent progressive deformity. ${ }^{7}$

\section{Indications of Surgical Intervention ${ }^{7}$}

1. Marked neurological deficit related to severe kyphosis, retropulsed bone or disc.

2. Advanced disease with marked bone destruction and threatened or actual severe kyphosis orparaplegia.

3. Progression of neurological deficit despite adequate chemotherapy.

4. Progression of kyphosis or instability despite adequate chemotherapy.

\section{Diagnosis $^{6,8}$}

A history of TB, a positive skin test and an elevated ESR are useful in the diagnosis of spinal TB. Radiology remains also essential in providing precious information for diagnosis and prognosis of spinal TB. Plain radiograph may show involvement of adjacent vertebrae with erosion of end plates. There may be significant kyphosis and paraspinal shadow, occasionally with involvement of posterior elements.

MRI is also useful in diagnosis of spinal TB in early and doubtful cases. MRI shows soft tissue including the spinal cord and its distortion by epidural collection. It may also show asymptomatic skip lesion away from the main disease.

CT scan is useful for appreciation of bone destruction and for needle aspiration or biopsy. CT guided biopsy and abscess drainage also aid in making the diagnosis. The use of DNA amplification technique (polymerase chain reaction or PCR) facilitates rapid and accurate diagnosis of the disease. Culturing the organisms 
is slow. Nevertheless, it is still a precious diagnostic method in order to recognize the causative organism.

Table I: Classification of tuberculosis paraplegia / tetraplegia ${ }^{9}$

\begin{tabular}{lll}
\hline \multicolumn{1}{c}{ Stage } & Clinical Feature \\
\hline I & Negligible & $\begin{array}{l}\text { Patient unaware of neural deficit, physician detects } \\
\text { plantar extensor and/or ankle clonus }\end{array}$ \\
II & Mild & $\begin{array}{l}\text { Patient is aware of deficit but manages to walk with } \\
\text { support }\end{array}$ \\
III & Moderate & $\begin{array}{l}\text { Non ambulatory because of paralysis (in extension), } \\
\text { sensory deficit }<50 \%\end{array}$ \\
IV $\quad$ Severe & $\begin{array}{l}\text { III }+ \text { flexor spasm/paralysis in flexion/flaccid/sensory } \\
\text { deficit }>50 \%\end{array}$ \\
\hline
\end{tabular}

\section{Materials and method}

This is a prospective interventional study carried out at National Institute of Traumatology \& Orthopaedic Rehabilitation (NITOR), Dhaka, Bangladesh and different private hospitals in Dhaka, Bangladesh from October 2012 to December 2014. Total number of patients were 12 having spinal tuberculosis in thoracic and lumbar region. They underwent posterior decompression, stabilization by transpedicular screws and rods and fusion. Among them 7 were male and 5 were female, age ranged from 21-60 years with a follow up period of 12 months to 18 months. Patients were selected on the basis of history, physical examination, hematological, radiological, MRI findings and in some cases CT guided FNAC. Patients were recruited on the basis of inclusion and exclusion criteria. In this study the patients were preoperatively classified according to American Spinal Injury Association (ASIA) Impairment Scale ${ }^{10}$ and among the 12 patients 1 was ASIA- A, 2 were ASIA-B, 5 were ASIA-C, 3 were ASIA-D, and 1 was ASIA-E. In postoperative state 1 patient was ASIA-B, 3 patients were ASIA-D and 8 were ASIA-E.

Table II: American Spinal Injury Association (ASIA) Impairment Scale

\begin{tabular}{ll}
\hline Grade A & Complete. No motor or sensory function is preserved in the sacral segments S4, S5. \\
Grade B & Incomplete sensory but not motor function is preserved below the neurological \\
& level and includes the sacral segments S4, S5. \\
Grade C & Incomplete motor function is preserved below the neurological level and more than \\
& half of a key muscle below the neurological level has a muscle grade less than 3. \\
Grade D & Incomplete motor function is preserved below the neurological level and at least \\
half of key muscles below the neurological level have a musclegrade of 3 or more.
\end{tabular}

\section{Inclusion Criteria}

1. All patients having spinal tuberculosis of thoracic and lumbar region.

2. Spinal TB with paraplegia.

3. Unstable spine due to spinal TB.

4. Age between 15-60 years.

\section{Exclusion Criteria}

1. Predestructive stage of tubercular spondylitis.

2. Spinal TB which response to Anti TB chemotherapy within 3-4 weeks.

3. Spinal TB over cervical region.

\section{Results}

Socio demographic variables including distribution of clinical presentation, lesion, and level of involvement are presented in table III.

Table III: Distribution of age, sex, occupation, clinical presentation, lesion \& level of involvement $(\mathrm{N}=12)$

\begin{tabular}{|c|c|c|}
\hline Variables & requency & Percentage (\%) \\
\hline \multicolumn{3}{|l|}{ Age in years } \\
\hline$<20$ & 1 & 8.33 \\
\hline $21-30$ & 5 & 41.67 \\
\hline $31-40$ & 3 & 25.00 \\
\hline $41-50$ & 2 & 16.67 \\
\hline $51-60$ & 1 & 8.33 \\
\hline \multicolumn{3}{|l|}{ Sex } \\
\hline Male & 7 & 58.33 \\
\hline Female & 5 & 41.67 \\
\hline \multicolumn{3}{|l|}{ Occupation } \\
\hline Day labourer & 3 & 25.00 \\
\hline Shopkeeper & 2 & 16.67 \\
\hline Serviceman & 1 & 8.33 \\
\hline Businessman & 1 & 8.33 \\
\hline Housewife & 5 & 54.67 \\
\hline \multicolumn{3}{|l|}{ Clinical Presentation* } \\
\hline Weakness & 2 & 16.67 \\
\hline Gibbus & 7 & 58.33 \\
\hline Pain & 10 & 83.33 \\
\hline Weight loss & 4 & 33.33 \\
\hline Stiffness & 1 & 8.33 \\
\hline Paraplegia & 6 & 50.00 \\
\hline Kyphoscoliosisdeformity & 1 & 8.33 \\
\hline Difficulty in walking & 2 & 16.67 \\
\hline \multicolumn{3}{|l|}{ Lesion } \\
\hline Dorsal & 7 & 58.33 \\
\hline Lumbar & 3 & 25.00 \\
\hline Dorsolumbar & 2 & 16.67 \\
\hline \multicolumn{3}{|l|}{ Level of involvement } \\
\hline D9- D10 & 1 & 8.33 \\
\hline D10 - D11 & 2 & 16.67 \\
\hline D11 - D12 & 4 & 33.33 \\
\hline D12 - L1 & 2 & 16.67 \\
\hline $\mathrm{L} 1$ - L2 & 2 & 16.67 \\
\hline L2- L3 & 1 & 8.33 \\
\hline
\end{tabular}


Table IV shows preoperative findings, pre and post operative kyphotic angle, pre and post operative ASIA grade, post operative complications and posterior fusion grades (Bridwell11 criteria)

Table IV: Distribution of preoperative findings, pre \& postoperative kyphotic angle, pre \& postoperative ASIA grade and postoperative complications $(\mathrm{N}=12)$

\begin{tabular}{|c|c|c|}
\hline Variables & Frequency & Percentage (\%) \\
\hline \multicolumn{3}{|l|}{ Preoperative findings } \\
\hline $\begin{array}{l}\text { Paradiscal lesion and paravertebral } \\
\text { abscess and necrosed caseous }\end{array}$ & 8 & 66.67 \\
\hline tissue and cord compression & & \\
\hline $\begin{array}{l}\text { Mechanical cord compression } \\
\text { by internal gibbus }\end{array}$ & 1 & 8.33 \\
\hline Peripheral cold abscess & 2 & 16.67 \\
\hline Extradural granuloma & 1 & 8.33 \\
\hline \multicolumn{3}{|l|}{ Preoperative kyphotic angle } \\
\hline$\leq 10^{\circ}$ & 6 & 50.00 \\
\hline $11-20^{\circ}$ & 1 & 8.33 \\
\hline $21-30^{\circ}$ & 3 & 25.00 \\
\hline $31-40^{\circ}$ & 1 & 8.33 \\
\hline$>40^{\circ}$ & 1 & 8.33 \\
\hline \multicolumn{3}{|l|}{ Postoperative kyphotic angle } \\
\hline$\leq 10^{\circ}$ & 10 & 83.33 \\
\hline $11-20^{\circ}$ & 1 & 8.33 \\
\hline $21-30^{\circ}$ & 1 & 8.33 \\
\hline $31-40^{\circ}$ & 0 & 0 \\
\hline$>40^{\circ}$ & 0 & 0 \\
\hline \multicolumn{3}{|l|}{ PreoperativeASIAgrade } \\
\hline Grade A & 1 & 8.33 \\
\hline Grade B & 2 & 16.67 \\
\hline Grade C & 5 & 41.67 \\
\hline Grade D & 3 & 25.00 \\
\hline Grade E & 1 & 8.30 \\
\hline \multicolumn{3}{|l|}{ Postoperative ASIA grade } \\
\hline Grade A & 0 & 0 \\
\hline Grade B & 1 & 8.33 \\
\hline Grade C & 0 & 0 \\
\hline Grade D & 3 & 25.00 \\
\hline Grade E & 8 & 66.67 \\
\hline \multicolumn{3}{|l|}{ Postoperative complications } \\
\hline Bed sore & 2 & 16.67 \\
\hline Wound infection & 1 & 8.33 \\
\hline No complications & 9 & 75.00 \\
\hline \multicolumn{3}{|l|}{ Posterior fusion grades } \\
\hline Grade 1 & 9 & 75.00 \\
\hline Grade 2 & 2 & 16.67 \\
\hline Grade 3 & 1 & 8.33 \\
\hline Grade 4 & 0 & 0 \\
\hline
\end{tabular}

Postoperative clinical outcome was evaluated by Modified Macnab criteria. ${ }^{12}$ Among 12 patients 7 $(58.33 \%)$ cases were excellent, $3(25 \%)$ cases were good, $1(8.33 \%)$ case was fair and $1(8.33 \%)$ case was poor. The overall result was analyzed by categorizing satisfactory (excellent and good) 10 $(83.33 \%)$ case and unsatisfactory $2(16.67 \%)$ cases (Table V).

\section{Table V: Post operative outcome $(\mathrm{N}=12)$}

\begin{tabular}{lcc}
\hline Outcome & Frequency & Percentage (\%) \\
\hline Functional outcome & & \\
Excellent & 7 & 58.33 \\
Good & 3 & 25.00 \\
Fair & 1 & 8.33 \\
Poor & 1 & 8.33 \\
Final outcome & & \\
Satisfactory & 10 & 83.33 \\
Unsatisfactory & 2 & 16.67 \\
\hline
\end{tabular}

\section{Follow up}

The detail follow up schedule for evaluation was selected to be conducted monthly for 3 months, then at 6 months, 9 months, 12 months and 18 months after surgery. The evaluation included clinical, haematological and radiological investigations. The clinical evaluation included functional assessment, local pain status, stability and mobility of spine, level of deformity of spine, motor score as motor strength of lower limb, walking ability, walking speed of lower limb, bowel and bladder and sensory improvement. Plain x-rayof dorsal and lumbar spine (AP \& lateralview) was done to see successful fusion and deformity correction. Hematological evaluations (ESR, CRP) were measured to determine the presence of active disease.

\section{Discussion}

The purpose of surgically treating dorsolumbar spine tuberculosis is to evacuate the abscess, excise the diseased tissue, and decompress neural tissue, maintenance of stability, early recovery and early rehabilitation. 
Spinal tuberculosis is common in 1 st three decades. ${ }^{7}$ In this study age of the patients varied from 20-60 years maximum was within 21-30 years. Here $58.33 \%$ cases were male and $41.67 \%$ cases were female. This finding is consistent with the study of Khoo et al. ${ }^{13}$

In this study most of the common clinical presentation was pain $(83.33 \%)$ followed by gibbus $(58.33 \%)$, paraplegia $(50 \%)$, weight loss $(33.33 \%)$, difficulty to working $(16.67 \%)$ and spinal deformity (8.33\%). Siddiqui et al. ${ }^{14}$ showed majority $(53.3 \%)$ patients had complaints of back pain while weakness in $17.8 \%$. In a study done by Polly \& Dunn ${ }^{15} 53 \%$ subjects had complaints of back pain. Garg et al. ${ }^{8}$ reported clinical features of spinal TB that includes local pain, local tenderness, stiffness and spasm of muscles, cold abscess, gibbus and prominent spinal deformity.

Regarding distribution of lesion $58.33 \%$ were dorsal, $25 \%$ were lumbar and $16.67 \%$ were dorsolumbar. Study by Godlwana et al. ${ }^{16}$ showed that thoracic spine was involved in $42 \%$ of cases, lumbar spine in $30 \%$ of cases and dorsolumbar in $10 \%$ cases.

In this study the kyphotic angle at preoperative state was compared with that at postoperative follow up. All patients showed a decrease in kyphotic angle in final follow up. This finding is consistent with the study of Jain et. al. ${ }^{17}$

In this study $8.33 \%$ patients were ASIA grade A, $16.67 \%$ were ASIA grade B, $41.67 \%$ were ASIA grade $C, 25 \%$ were ASIA grade D and $8.33 \%$ were ASIA grade $\mathrm{E}$ in preoperative state. On the other hand in postoperative state $8.33 \%$ were ASIA grade B, 25\% were ASIA grade D and $66.67 \%$ were ASIA grade E. This difference was statistically significant. Study done by Gupta et al. ${ }^{18}$ showed that before starting treatment, $2.08 \%$ patients were in ASIA A, $4.16 \%$ were in ASIA B, $18.75 \%$ were in ASIA C, $75 \%$ were in ASIA D and $20 \%$ were in ASIA E. After 6 months of therapy $90 \%$ patients were in ASIA D and $55.5 \%$ in ASIA
C had complete neurological recovery. Both patients from ASIA B improved to ASIA D. Single patient who was in ASIA A before treatment remained non-ambulatory ASIA C after treatment. They also found significant difference between before treatment and 6 months after therapy.

Regarding the posterior fusion, grade I fusion was found in $75 \%$, grade II fusion in $16.67 \%$ and grade III fusion in $8.33 \%$ cases. This finding is consistent with the findings of Garg et al. ${ }^{8}$ They found grade I fusion in $72.2 \%$, grade II fusion in $25 \%$ and grade III in $2.8 \%$ of patients.

Regarding the subjective assessment of this series, it was observed that $(58.33 \%)$ patients had excellent functional outcome, $3(25 \%)$ patients had good, $1(8.33 \%)$ patient had fair and $1(8.33 \%)$ patient had poor functional outcome.

In this study overall a satisfactory (excellent and good) result was found in $10(83.33 \%)$ patients and unsatisfactory (fair and poor) resultin3 $(16.66 \%)$ patients.

\section{Conclusion}

If patients have milder form of spinal TB and are diagnosed earlier, conservative management consisting of Anti TB chemotherapy and orthosis is the treatment of choice. In those where conservative management has failed and the patient is developing progressive kyphotic deformity and/or progressive neurological deficit and/or progressive instability, surgical intervention is indicated. Based on the result shown above it can be concluded that surgical procedure specially posterior decompression, stabilization by transpedicular screws and rods and fusion is an effective, safe and acceptable procedure for patients with spinal TB in thoracic and lumbar region. Posterior approach is a minimum surgical intervention and easy approach that encourages neurological recovery, good correction of kyphosis and prevention of further progressive kyphosis. 


\section{References}

1. Tuli SM. Tuberculosis of the Skeletal System. 3rd ed. New Delhi: Jaypee Brothers Medical Publishers; 2004. p.191-94.

2. Rob A, Zahiruddin AKM. Dorsolumbar Spinal Tuberculosis and Its Surgical Management. The Journal of Bangladesh Orthopaedic Society. 2013;28(2):192-96.

3. Jain AK, Dhammi IK, Jain S, Mishra P. Kyphosis in Spinal Tuberculosis - Prevention and Correction. Indian J Orthop. 2010;44(2):127-36.

4. Solomon L, Warwick DJ, Nayagam S. Apley's System of Orthopaedics and Fractures. 8th ed. London: Arnold; 2001. p.387-89.

5. Jain AK. Tuberculosis of the Spine: a Fresh Look at an Old Disease. J Bone Joint Surg Br. 2010;92(7):905-13.

6. Rasouli MR, Mirkoohi M, Vaccaro AR, Yarandi KK, Rahimi-Movaghar V. Spinal Tuberculosis: Diagnosis and Management. Asian Spine J. 2012;6(4):294-308.

7. Rajasekaran S. The Problem of Deformity in Spinal Tuberculosis. Clin Orthop Relat Res. 2002; 398:85-92.

8. Garg B, Kandwal P, Upendra BN, Goswami A, Jayaswal A. Anterior Versus Posterior Procedure for Surgical Treatment of Thoracolumbar Tuberculosis: a Retrospective Analysis. Indian J Orthop. 2012;46(2):165-70.

9. Agrawal V, Patgaonkar PR, Nagariya SP. Tuberculosis of Spine. J Craniovertebr Junction Spine. 2010;1(2):74-85.

10. KirshblumSC, Burns SP, Biering-Sorensen F, Donovan W, Graves DE, Jha A, et al. International Standards for Neurological Classification of Spinal Cord Injury (Revised 2011). J Spinal Cord Med. 2011; 34(6):535-46.
11. Bridwell KH, Lenke LG, McEnery KW, Baldus C, Blanke K. Anterior Fresh Frozen Structural Allografts in the Thoracic and Lumbar Spine. Spine (Phila Pa 1976). 1995;20:1410-18.

12. Macnab I. Negative Disc Exploration: an Analysis of the Cause of Nerve Root Involvement in Sixty-Eight Patients. J Bone Joint Surg. 1971;53:891-903

13. Khoo LT, Mikawa K, Fessler RG. A Surgical Revisitation of Pott Distemper of the Spine. Spine J. 2003;3:130-45.

14. Siddiqui AI, Abro HA, Phulpoto M. Clinico-Radiological Presentation of the Patients with Pott's Disease, 3 Years Experience at Department of Neurology, Chandka Medical College Hospital (SMBBMU) Larkana. Medical Channel. 2013;19(4):14-16.

15. Polley P, Dunn R. Noncontiguous Spinal Tuberculosis: Incidence and Management. Eur Spine J. 2009;18(8);1096-101.

16. Godlwana L, Gounden P, Ngubo P, Nsibande T, Nyawo K, Puckree T. Incidence and Profile of Spinal Tuberculosis in Patients at the Only Public Hospital Admitting Such Patients in KwaZulu-Natal. Spinal Cord. 2008;46(5):372-34.

17. Jain AK, Dhammi IK, Prashad B, Sinha S, Mishra P. Simultaneous Anterior Decompression and Posterior Instrumentation of the Tuberculous Spine Using an Anterolateral Extrapleural Approach. J Bone Joint Surg Br. 2008;90:1477-81.

18. Gupta AK, Kumar C, Kumar P, Verma AK, Nath R, Kulkarni CD. Correlation between Neurological Recovery and Magnetic Resonance Imaging in Pott's Paraplegia. Indian J Orthop. 2014;48:366-73. 